\title{
Operational parameters affecting the removal and recycling of direct blue industrial dye from wastewater using bleached oil mill waste as alternative adsorbent material
}

\author{
Vito Rizzi ${ }^{1}$, Chiara Mongiovì ${ }^{1}$, Paola Fini ${ }^{2}$, Andrea Petrella ${ }^{3}$, Paola Semeraro ${ }^{1}$, Pinalysa \\ Cosma $^{1 *}$ \\ ${ }^{1}$ Università degli Studi “Aldo Moro" di Bari, Dip. Chimica, Via Orabona, 4- 70126 Bari, Italy, \\ ${ }^{2}$ Consiglio Nazionale delle Ricerche CNR-IPCF, UOS Bari, Via Orabona, 4- 70126 Bari, Italy \\ ${ }^{3}$ Dipartimento di Ingegneria Civile, Ambientale, Edile, del Territorio e di Chimica, Politecnico di Bari, Orabona, 4, 70125, \\ Bari, Italy
}

\begin{abstract}
In this work the ability of "bleached" oil mill solid waste to reduce the dyestuff content in industrial textile wastewater was studied. Bleaching treatment consists in a preliminary oil mill solid waste management with $\mathrm{NaOH}$ and $\mathrm{NaClO}_{2}$ for obtaining cellulosic materials, mainly removing lignin from the waste surface. Thus, a novel bioadsorbent from agricultural residues, named bleached olive pomace $(O P)$, was presented. Direct Blue 78 was studied as a model azoic dye. Experiments were planned to study the effect of different initial conditions on the adsorption processes: oil mill waste amount as grains and as a fine powder $\left(O P_{P}\right)$, solution temperature values, initial dye concentration, $p H$ values and electrolytes influence. The results showed that the adsorption process using bleached oil mill waste determined an excellent degree of water color reduction, reaching the best work conditions when $\mathrm{pH} 2$ and $O \mathrm{P}_{\mathrm{P}}$ were used. The presence of electrostatic interactions was also suggested. The adsorption appeared to be influenced by temperature values showing an endothermic character. Interestingly, to confirm the role of ionic interactions between dye and sorbent at $\mathrm{pH} 2$, fashionable results were obtained. The adsorption process was verified also at $\mathrm{pH} 6$ with $100 \%$ of dye removal in presence of both $\mathrm{NaCl}$ and $\mathrm{Na}_{2} \mathrm{SO}_{4}$ avoiding the aforementioned strong acid conditions. A very important aspect of this work is the recycle of both the dye and the adsorbent, with particular attention to the dye reuse for coloring cotton fabric.
\end{abstract}

Keywords - Adsorbent recycle, adsorption, bleaching process, Olive pomace, textile dyes.

\section{INTRODUCTION}

In this generation, environmental questions such as water contamination are becoming progressively important.[1]
As reported recently by Ertugay et al.[2] more than 25\% of the total world population suffers from health and hygienic problems related to pollutant inflowing water.[2] Indeed, with the human development and improvement of technologies, large amounts of wastes are discharged every day into water. The composition of these pollutants encompasses a variety of contaminants as heavy metals, dyes, and/or other undesirable chemical compounds. The problem get worst and becomes more serious when dyes from textile industries flow into the water.[1,3] The nature of dyestuffs is very large and they are usually classified in accordance with the dyeing processes: some interact by ionic bonds or form covalent bonds or interact by electrostatic forces, and others interact by hydrophobic forces. It is worth to mention that among these, azo dyes are the dominant class among commercial dyes and belong to the category of direct dyes, largely used to color cellulose fibers mainly interacting through hydrophobic forces.[4] Nonetheless, the release of azo dyes into environment is of great concern, due to both their highly visible color in water, and their toxicity, mutagenicity and carcinogenicity, it still continues to find new applications in high-technology areas.[5,6] Although the amount of discharged dyes in water is not exactly known, recently Pirkarami et al.[7] reported that more than 5000 tons of dyeing materials are drained into the environment every year, affecting the human life and the global ecosystem.[7] Indeed, dyes are stable to light and heat, they have a high organic content, and the most part of them have complex aromatic structures not biodegradable.[8] As a result, the removal of synthetic dyes from industrial effluents is a great actual challenge. In this field the Authors of this paper have years of experience presenting innovative methods and materials with great performances in 
decoloring wastewater.[9-12] Overall, for these purposes, physical adsorption is presented as a simple method with several advantages: ease of operations, simplicity of design, high efficiency and low cost applications in water decoloration processes. Among adsorbent materials for wastewater treatment, the agricultural wastes are very interesting sorbent materials requiring little processing, but showing good adsorption capacity, selectivity, low cost, free availability and easy regeneration. However, as reported by Sayğili et al.[8], the application of untreated agricultural or plant wastes as adsorbents can also bring several problems and then, with the aim of improving their performance, the wastes are modified with different reagents and methods.[8] Regarding to the adsorbent used in this paper, i.e. oil mill solid residue (olive pomace), a chemical treatment by means of acids, bases or $\mathrm{H}_{2} \mathrm{O}_{2}$ are generally proposed in literature.[13] As alternative, the thermal pretreatments is also suggested, with the most part of papers related to the achievement of active carbon from oil mill solid waste. In this context, as recently evidenced by ourselves[9], a very deep survey of papers related to the olive pomace use in dye removal from water showed as the number of publications was not high, being the most part of them focused on the heavy metal removal or requiring strong pre-treatment conditions.[9] In the same paper, we presented the performance of the olive pomace in removing disperse dyes from wastewater, by previously adsorbent treatment in hot water at $100^{\circ} \mathrm{C}$, showing also the recycle of both the adsorbent material and dyes.[9]

In this article, we show the best conditions adoptable to eliminate another class of dyes, direct dyes, from water enabling also the possibility to recover and reuse the dye itself. For the first time, the olive pomace was treated with $\mathrm{NaOH}$ and $\mathrm{NaClO}_{2} /$ acetic acid (bleaching process) to gradually remove lignin and holocellulose, in turn restituting mainly cellulose characterized by a high affinity with azo dyes.[14] Indeed, this procedure is usually used to obtain cellulose material from natural plant fibers.[15] As for the adopted model dye, Direct Blue 78 (DB) received by Colorprint Fashion, a Spanish textile industry, was used to reduce the contamination of colored water used for dyeing processes. Overall, effluent treatments aiming to reduce the amount of dyes having a structure similar to DB, are known in literature, as for example degradation methods through Fenton's oxidation process.[2]

The Direct Blue 78 photocatalytic degradation using $\mathrm{TiO}_{2}$ nanoparticles immobilized on recycled wool-based nonwoven material, was presented by Markovic et al.[16] The DB 71 adsorption from aqueous solution onto pistachio hull waste as a low-cost adsorbent was also presented by Biglari et al.[17] Activated carbon and poly pyrrole polymer composite prepared from Thevetia Peruviana were presented as materials to adsorb DB 71 .
[18] Without doubt the list is not complete for describing the plethora of studies in literature about the azoic blue dye removal or its degradation in aqueous environment, however in the present paper we highlight the use of a handy material exhibiting very high capabilities in sequestering the direct dye within few minutes in appropriate conditions. Moreover the recycle of DB 78 by means of desorption was obtained, enabling the possibility to color again cotton fibers, with

3 an environmental friendly green cycle and an alternative use of oil mill waste. As a whole the environmental disorder was reduced.

\section{MATERIALS AND METHODS}

2.1 Chemicals. All the chemicals used were of analytical grade and samples were prepared using double distilled water. Direct Blue 78 (chemical formula: $\mathrm{C}_{42} \mathrm{H}_{25} \mathrm{~N}_{7} \mathrm{Na}_{4} \mathrm{O}_{13} \mathrm{~S}_{4}$, MW: $1055.1 \mathrm{~g} \times \mathrm{mol}^{-1}$ ) reported in Scheme 1, was received by Colorprint Fashion, S.L and used without further purification. Dye stock solutions with a concentration of $1.0 \times 10^{-4} \mathrm{M}$ were prepared and dilutions were carried out with double distilled water in order to obtain different dye concentrations namely $5 \times$ $10^{-5} \mathrm{M}$ and $1.0 \times 10^{-5} \mathrm{M}$. The $\mathrm{pH}$ of the various aqueous solutions was adjusted using concentrated $\mathrm{HCl}$ and $\mathrm{NaOH}$ solutions. $\mathrm{NaOH}$ and $\mathrm{HCl}$ were purchased from SigmaAldrich (Milan, Italy). The same commercial source was also adopted for the following chemicals: Acetic acid (99,9 $\%$ ), $\mathrm{NaClO}_{2}, \mathrm{NaCl}$ and $\mathrm{Na}_{2} \mathrm{SO}_{4}$.

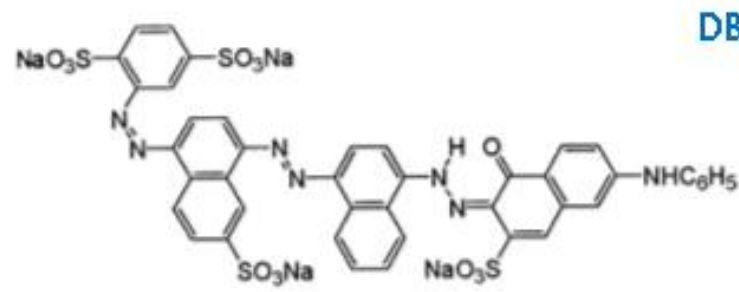

Scheme.1: Chemical structure of Direct Blue 78.

2.2 Preparation of the biosorbent. The biosorbent material was the solid waste of oil mill named Olive Pomace (OP), obtained during the oil production. OP was obtained from a local oil mill settled in Bari, south of Italy. OP was treated exploiting a procedure generally used to bleach natural fibers for removing impurities, lignin and holocellulose.[14,15] Several experimental conditions were studied, however among these the following procedure was proposed in this paper:

a) Alkaline treatment: $26.00 \mathrm{~g}$ of OP were boiled, for 2 $\mathrm{h}$, in $140 \mathrm{~mL} \mathrm{NaOH} 3 \mathrm{M}$ with continuous magnetic stirring.

b) Bleaching: The OP was subsequently boiled, for $2 \mathrm{~h}$, in $70 \mathrm{~mL}$ of $\mathrm{NaClO}_{2} 1,7 \% \mathrm{w} / \mathrm{w}$ and $70 \mathrm{~mL}$ of Acetic buffer, $0.5 \mathrm{M}$. 
The experiments were performed both using OP as obtained after the treatment and sieved $\left(\mathrm{OP}_{\mathrm{P}}\right)$ obtaining a fine powder.

2.3 Experimental procedures. The experiments were conducted in $10 \mathrm{~mL}$ glass beakers containing known concentrations of dye solutions. The effects of the biosorbent and dye dosages on dye removal from wastewater, were assessed changing the amount of OP/OP , from 0.10 to $1.00 \mathrm{~g}$, at $5 \times 10^{-5} \mathrm{M}$ and $1 \times 10^{-5} \mathrm{M}$ of dye concentration. The effect of both temperature and salt concentration were also evaluated in the range $25 \div 70^{\circ} \mathrm{C}$ and $5 \times 10^{-3} \mathrm{M} \div 1 \mathrm{M}$, respectively. The mixtures were stirred at $140 \mathrm{rpm}$ for different contact times using a digitally controlled magnetic stirrer. The adsorption process was studied following the DB absorption spectrum evolution at $600 \mathrm{~nm}$ when the solution was in contact with the pomace. In accordance with papers reported in literature[9] the adsorption capacity $\mathrm{q}_{\mathrm{t}}\left(\mathrm{mg} \times \mathrm{g}^{-1}\right)$ at time $t$ of dye, was inferred by applying the following equation (1):

$\mathrm{q}_{\mathrm{t}}=\frac{\mathrm{C}_{0}-\mathrm{C}_{\mathrm{t}}}{\mathrm{W}} \times V$

Equation 1

where $V$ represents the adopted total volume of solution (herein $10 \mathrm{~mL}$ ), $W$ is the weight of the dry adsorbent material $(\mathrm{g}), C_{0}$ and $C_{t}$ represent the initial concentration and the concentration at time $t$ of the dye $\left(\mathrm{mg} \times \mathrm{L}^{-1}\right)$.

2.4 Desorption studies. The DB desorption studies from pomace surface were carried out by using a basic solution at $\mathrm{pH}$ 12. The olive pomace was loaded with dye's initial concentration $\left(5 \times 10^{-5} \mathrm{M}\right.$ in $10 \mathrm{~mL}$ at $\left.\mathrm{pH} 2\right)$ for 15 minutes. The dye loaded pomace samples were separated from the initial dye solutions, then washed with distilled water for the removal of unadsorbed dye and placed in contact with $10 \mathrm{~mL}$ of a $0.01 \mathrm{M}$ of $\mathrm{NaOH}$ solution. The efficiency of desorption was calculated by using the following equation: where $m_{\mathrm{d}}$ is the amount of dye desorbed and $m_{\mathrm{a}}$ is the amount of dye adsorbed.

$$
\mathrm{E} \%=\frac{\mathrm{m}_{\mathrm{d}}}{\mathrm{m}_{\mathrm{a}}} \times 100
$$

Equation 2

The same Equation was used to calculate also the efficiency of adsorbed dye. In that case $m_{\mathrm{d}}$ is the amount of dye adsorbed and $m_{\mathrm{a}}$ is the initial amount of dye.

2.5 Dyeing experiments. The dyeing experiments were performed dyeing cotton pieces $(1 \mathrm{~cm} \times 1 \mathrm{~cm})$ for 60 minutes at $95^{\circ} \mathrm{C}$ in presence of increasing amounts of sodium sulfate to promote the dye exhaustion, that is the process of dye transferring from the water to cotton fibers.

\subsection{Visible and FTIR-ATR spectroscopic} measurements. Visible absorption spectra were recorded using a Varian CARY 5 UV-Vis-NIR spectrophotometer (Varian Inc., now Agilent Technologies Inc., Santa Clara, CA, USA). FTIR-ATR spectra were recorded within the $600-4000 \mathrm{~cm}^{-1}$ range using an Fourier Transform Infrared spectrometer 670-IR (Varian Inc., now Agilent Technologies Inc., Santa Clara, CA, USA), whose resolution was set to $4 \mathrm{~cm}^{-1} .32$ scans were summed for each acquisition.

2.7 Scanning Electron Microscopy (SEM). In the case of SEM analysis, an electron microscope FESEM-EDX Carl Zeiss Sigma 300 VP was used. The samples were fixed on aluminum stubs and then sputtered with graphite by the use of a Sputter Quorum Q150.

\section{RESULTS AND DISCUSSIONS}

Fig. 1 (panels A and B) reports the SEM images of the adsorbent material. The morphology investigation shows the presence of irregular domains that conferred to OP the important features to be a material having a high porous character. In detail, Fig. 1A and Fig. 1B show OP before and after the adopted bleaching process, respectively. Interestingly, as it can be seen directly from Fig. 1B, the surface of the biosorbent occurred not affected by the bleaching process, maintaining the porous surface already observed in Figure 1A, which can be better appreciated in Fig. 1C. Indeed, changing the magnification ratio, the presence of cavities and irregular islands are better evidenced in that figure enabling OP to host dye molecules from aqueous solutions.
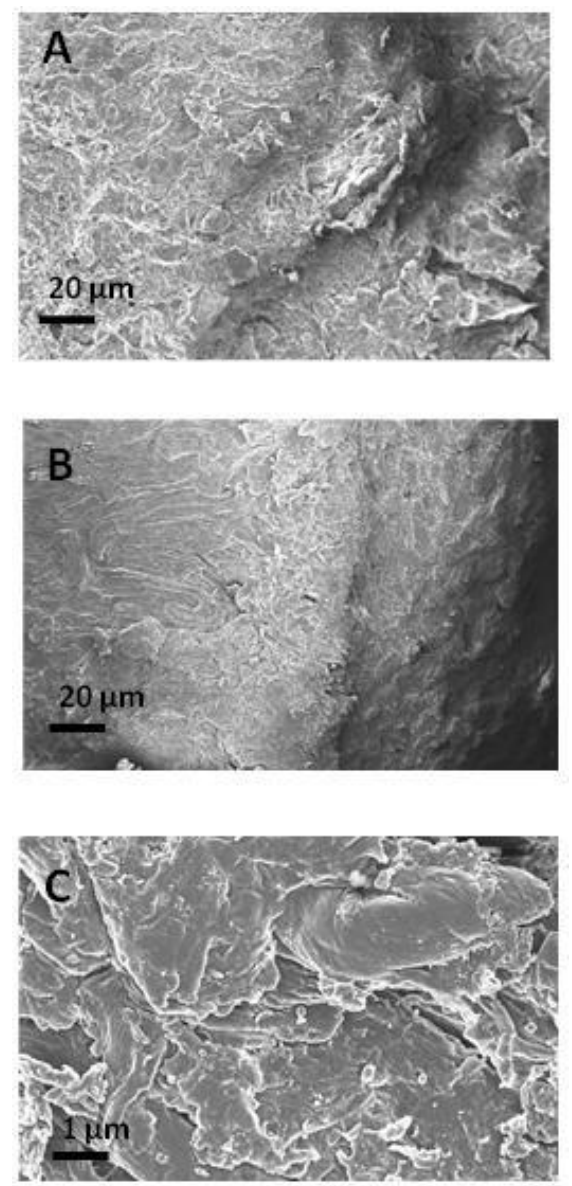

Fig. 1: SEM images of olive pomace before (A) and after the treatments with a scale bar of $20 \mu \mathrm{m}(B)$ and $1 \mu \mathrm{m}(C)$. 
OP was recently presented in literature by ourselves for the removal and recover of a disperse dye from wastewater, using OP simply washed with hot water in order to remove impurities.[9] Using the OP treated in the same way for removing direct azo dyes (data not shown), it is possible to obtain the dye removal, but not its recovery. This led us to change the treatment procedure of biosorbent, obtaining also a quick dye removal using suitable conditions of work. In detail, the OP was subjected to an alkaline treatment followed by a bleaching procedure. The changes induced by these new processes can be appreciated observing the FTIR-ATR spectra reported in Fig. 2A and Fig. 2B. Before the treatment (Fig. 2A), OP showed typical bands indicating the presence of lignin, cellulose and celluloselike structures as main components.[9]
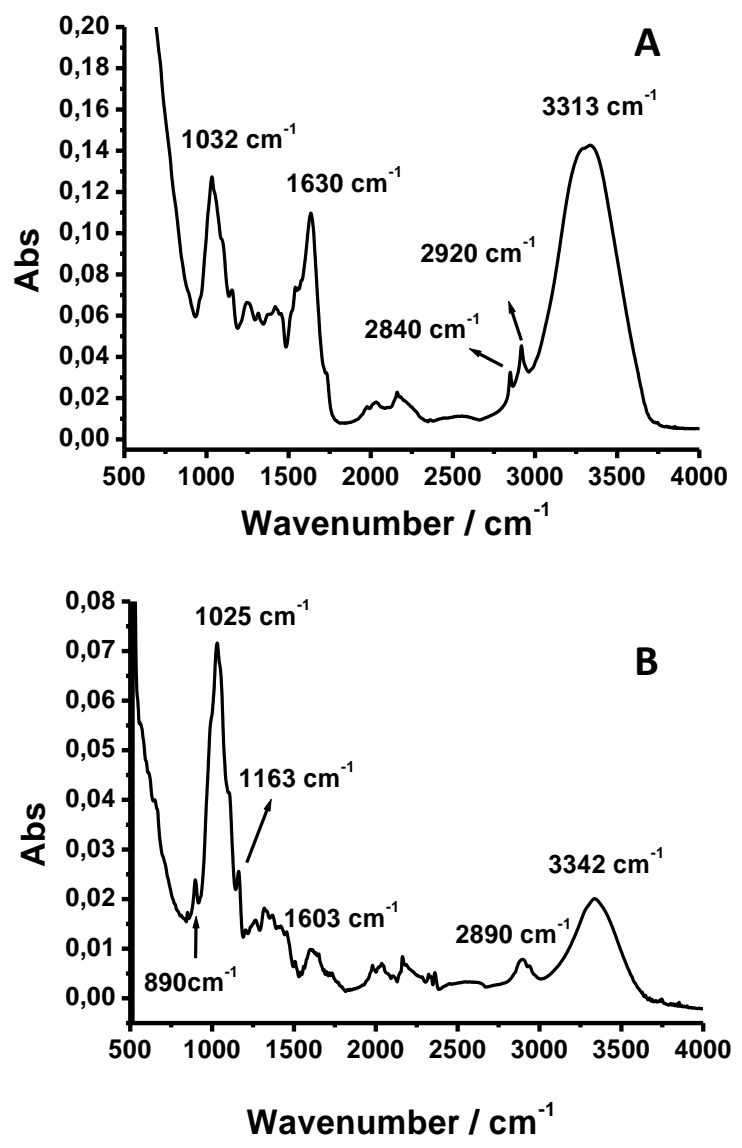

Fig. 2: Comparison between detailed views (wavenumbers range: $500-4000 \mathrm{~cm}-1$ ) of FTIR-ATR spectra of olive pomace before $(A)$ and after the treatments $(B)$.
Along with bands at $2920 \mathrm{~cm}^{-1}$ and $2840 \mathrm{~cm}^{-1}$ evidencing the presence of lignin and carbohydrates, signals in the region $1520-1540 \mathrm{~cm}^{-1}$ indicated the presence of esters in the lignin structure. The bending vibrations of aliphatic $\mathrm{CH}$ were also observed at $1366-1320 \mathrm{~cm}^{-1}$. Bands at 1540 $\mathrm{cm}^{-1}$ and $1630 \mathrm{~cm}^{-1}$ suggested the presence of amino and carboxyl groups, respectively.

Not surprisingly, an intense band was detected at $3313 \mathrm{~cm}^{-}$ 1 and ascribable to the hydroxyl and amino group stretching. The broad bands at 1160-1000 $\mathrm{cm}^{-1}$ represented the characteristic $\mathrm{C}-\mathrm{O}-\mathrm{C}$ and $\mathrm{OH}$ vibrations of polysaccharides and, among them, of cellulose. When the bleaching process was applied to OP, the variation on the material surface, ascribable to changes of natural polysaccharides, modified the corresponding FTIR-ATR spectrum (Fig. 2B). Indeed, after the treatment, significant variations were observed in the fingerprint region affecting mainly the signals of lignin. In particular, the bands at about $1630 \mathrm{~cm}^{-1}$ and $1032 \mathrm{~cm}^{-1}$ (Fig. 2A) changed their ratio with the latter signal that moved to $1025 \mathrm{~cm}^{-1}$ (Fig. 2B). Along with these variations the signals detected at $3313 \mathrm{~cm}^{-1}$ before the treatment (Fig. 2A) shifted at about $3342 \mathrm{~cm}^{-1}$ indicating the main presence of $\mathrm{O}-\mathrm{H}$ stretching modes of wood fibers (Fig. 2B).[19-23] Moreover, as indicated by Kondo, this signal can be ascribed to a peculiar intramolecular hydrogen bond in cellulose structure.[24] As suggested by Poletto et al.[25] the band at about $2890 \mathrm{~cm}^{-1}$ (Fig. 2B) indicated the stretching vibration mode of methyl and methylene groups present in the spectra of all of the fiber components, but mainly in the spectrum of cellulose.[25] Bands detected at $1600 \mathrm{~cm}^{-1}$ and below this region, when the treated sample is considered (Fig. 2B), were assigned to $\mathrm{C}-\mathrm{H}$ and $\mathrm{C}-\mathrm{O}$ deformation, i.e. bending or stretching vibrations of carbohydrates. Not surprisingly, the deformation or stretching vibrations, observed at 1163 and $1025 \mathrm{~cm}^{-1}$, confirm the presence of $\mathrm{C}-\mathrm{O}-\mathrm{C}$ and $\mathrm{C}-\mathrm{O}$ groups.[25] Overall results suggested that lignin was the main component removed during the treatment, with the remaining adsorbent material largely composed by cellulose and cellulose-like structures with traces of lignin.[9,14,15] 


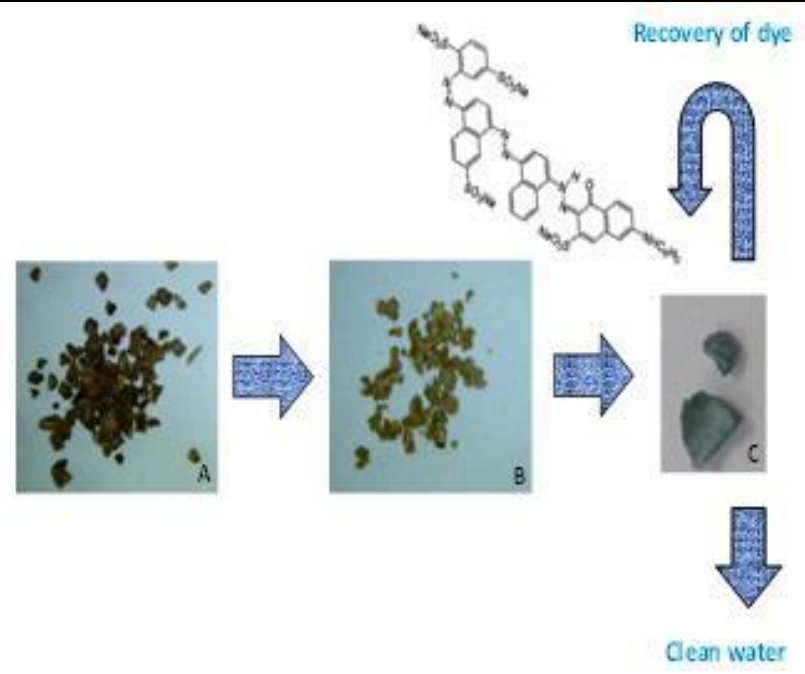

Fig. 3: Camera pictures of $O P$ as appear before (A) and after the treatments (B). Treated OP after the adsorption of DB (C). The amount of pomace and dye were settled at $0.25 \mathrm{~g}$ and $5 \times 10-5 \mathrm{M}$ in $10 \mathrm{~mL}$, respectively. The reuse of both the dye and adsorbed material is also depicted.

The removal of lignin was also confirmed by observing Fig. 3A and Fig. 3B that show as the color of the adsorbent changed after the treatments: olive pomace grains altered their color from dark brown to yellow, when the bleaching process was performed (Fig. 3B). The removal of lignin could be considered as the main factor inducing these chromatic changes. As well as to SEM images (Fig. 1), these camera pictures offer a macroscopic view of the pomace aspect, confirming the irregular character of the material offering active sites to host dye molecules. The dye used in this paper, as an example of direct ionic azo dyes, was Direct Blue 78 (DB78, See Scheme 1). The dye was removed from water with an excellent performance by means of adsorption process on treated OP surface. However, particular conditions of work must be adopted and will presented in the next section of the manuscript. As it can be seen macroscopically, by observing the OP camera pictures in Fig. 3C, the OP grains in contact with DB78 solutions changed their color from yellow to blue, indicating the uptake of dye molecules from wastewater. The dye recovery was also obtained offering the possibility to open a green virtuous cycle in which both the adsorbent and the dye can be re-used.

\subsection{Adsorption experiments.}

3.1.1 Effect of pH. As a first step of this study, $1.00 \mathrm{~g}$ of $\mathrm{OP}$ as grains was placed in wastewater containing DB dye and the UV-Vis absorption spectra were collected each 30 minutes monitoring the DB78 absorption maximum at 600 nm (Fig. 4).
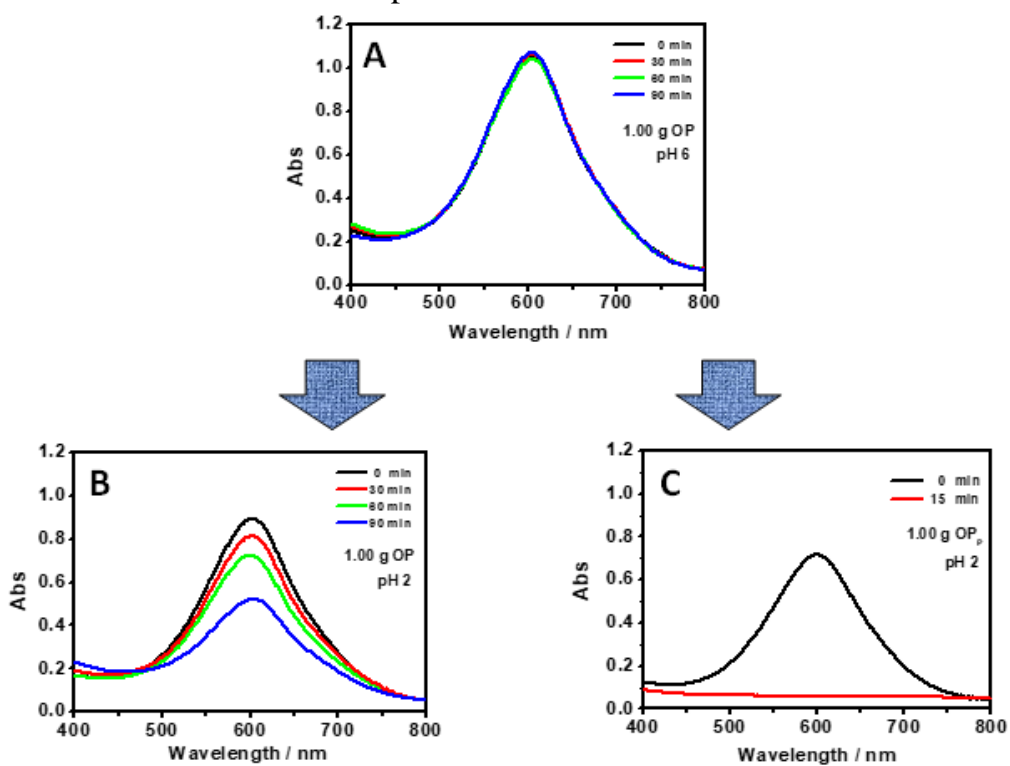

Fig. 4: Visible absorption spectra of DB78 dye obtained at several contact time when the dye solution was in contact with $1.00 \mathrm{~g}$ of olive pomace as a grains, $\mathrm{pH} 6(\boldsymbol{A})$ and $\mathrm{pH} 2(\boldsymbol{B})$ and powdered, $\mathrm{pH} 2(\boldsymbol{C})$. The dye concentration was settled at $5 \times 10^{-5} \mathrm{M}$ in $10 \mathrm{~mL}$. 
Before the measurements, the sample at $\mathrm{pH} 6$ was centrifugated and the surnatant was subject to the spectroscopic analysis. The absence of results (Fig. 4a) induced us to change the solution $\mathrm{pH}$. Interestingly, when the $\mathrm{pH}$ was decreased to $\mathrm{pH} 2$, important results were obtained with the $50 \%$ of dye molecules removed from water in 90 minutes, if OP was used as grains (Fig. 4B). Interestingly, by using the same amount of pomace, but crushed in fine powder, extraordinary results were observed: only 15 minutes were necessary to completely remove the dye from the solution (Fig. 4C). The efficiency of $100 \%$ was thus presented. For that reason, the study was focused on the pomace reduced in fine powder $\left(\mathrm{OP}_{\mathrm{P}}\right)$ as biosorbent and the effect of solution $\mathrm{pH}$ values was evaluated in the range 2-12. The amount of pomace and dye were settled at $0.25 \mathrm{~g}$ and $5 \times 10^{-5} \mathrm{M}$ in $10 \mathrm{~mL}$, respectively.

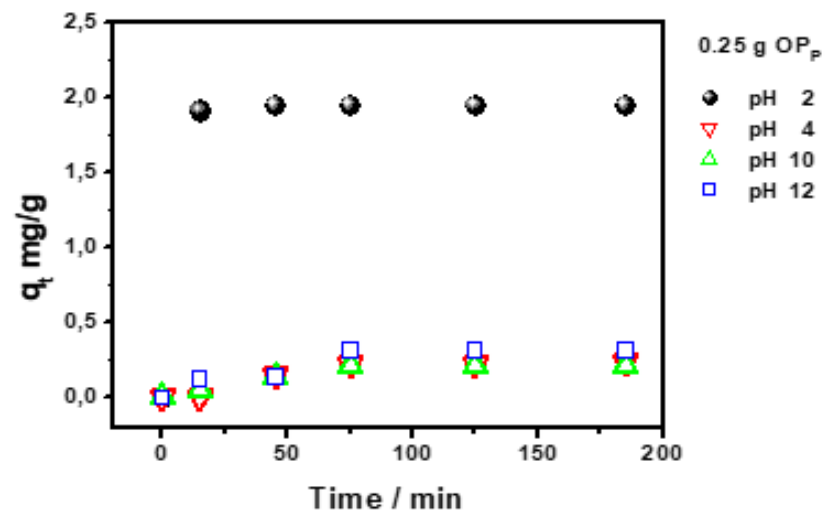

Fig. 5: Effect of solution $p H$ values, ranging from 2 to 12, on the adsorption capacity $q t(m g \times g-1)$ of DB78 removal from aqueous $(5 \times 10-5 \mathrm{M})$ solutions, at fixed OPP amount $(0.25 \mathrm{~g})$.

In order to better evidences the effect of various $\mathrm{pHs}$ affecting the DB78 removal from water, the $\mathrm{q}_{\mathrm{t}}$ values (using (1)) were calculated and compared in Fig. 5. Clearly, it is evident that the dye removal from wastewater was obtained only at $\mathrm{pH} 2$, with slight and not important variations at the other $\mathrm{pH}$ values ranging from 4 to 12 . To better explain this finding, it is noteworthy that DB78 is a ionic negatively charged dye that in aqueous solution carries a net negative charge due to the presence of sulfonate groups. The UV-Vis absorption spectra of DB78 reported in Fig. 4 suggested as the dye was almost insensitive to the acidity of the solution. The typical absorption band, located at about 550-600 nm, attributable to the characteristic chromophoric part of the dyes comprising the azo-groups $(-\mathrm{N}=\mathrm{N}-$ ) interacting with the adjacent aromatic moieties, was detected. The lack of spectral modifications in the wavelength position of the dye aqueous solutions at different $\mathrm{pHs}$, suggested the $\pi \rightarrow \pi^{*}$ nature of that band. While, the change in the signal intensity could be attributed to the protonation of the central secondary amino group $\left(\mathrm{pK}_{\mathrm{a}}<4\right)$. The sulfonate groups, can be considered deprotonated in the adopted range of $\mathrm{pH}$ values, due to their $\mathrm{pK}_{\mathrm{a}}<2$.[26,27]

These results were in excellent agreement with the considerations reported by Abbott et al.[5] about the role of $\mathrm{pH}$ values on the $\mathrm{pH}$-dependent equilibrium forms of DB78.[5] Consequently, in our condition, as well described by Sayğili et al. [8] in their studies related to the chemical modification of a cellulose-based material to improve its adsorption capacity for anionic dyes, at the increasing of the dye solution $\mathrm{pH}$, the adsorptions of the dye decreased due to the electrostatic repulsion between the negatively charged pomace surface and DB78 charges.[8] Moreover, in presence of $\mathrm{OH}^{-}$ions in excess, these efficiently competed with dye anions for the adsorption sites onto the sorbent surface. While, Safa $e t$ al.[29] described that, lowering the $\mathrm{pH}$ values, the concentration of $\mathrm{H}^{+}$ions increased, positively charging the surface of the biomass. In that condition electrostatic interactions between positively charged biomass surface and negatively charged dye molecules could be taken in account.[29] The nature of electrostatic interactions was confirmed when $\mathrm{OP}_{\mathrm{P}}$ after the adsorption of DB78 dye (at $0.25 \mathrm{~g}$ of pomace and $5 \times 10^{-5} \mathrm{M}$ of DB78 in $10 \mathrm{~mL}$ ) was placed in contact with a basic solution containing $\mathrm{NaOH}$ $(0.01 \mathrm{M})$, at $\mathrm{pH} 12$. Preliminary the $\mathrm{OP}_{\mathrm{P}}$ loaded with DB78 was carefully washed with water in order remove unadsorbed dye molecules and then was placed in a solution at $\mathrm{pH}$ 12. By using (2), the efficiency of the dye desorption was evaluated: the $70 \%$ of the adsorbed dye was recovered after $1 \mathrm{~h}$ (see Table 1 , the first cycle of adsorption/desorption).

Table 1: Experiments of adsorption/desorption of DB78 at concentration of $5 \times 10^{-5} \mathrm{M}$ (Volume: $\left.10 \mathrm{~mL}\right)$, at a fixed amount of $O P_{P}(0.25 \mathrm{~g})$, on the contact time enough to

obtain the reported uptake or the recovery of dye molecules from aqueous solutions at pH 12 (Volume: 10

\begin{tabular}{|c|c|c|c|}
\hline \multicolumn{4}{|c|}{$m L)$. } \\
\hline CYCLES & & Efficiency (\%) & Time (min) \\
\hline \multirow[t]{2}{*}{1} & ADSORPTION & 100 & 15 \\
\hline & DESORPTION & 70 & 60 \\
\hline \multirow[t]{2}{*}{2} & ADSORPTION & 100 & 30 \\
\hline & DESORPTION & 80 & 60 \\
\hline \multirow[t]{2}{*}{3} & ADSORPTION & 100 & 30 \\
\hline & DESORPTION & 90 & 60 \\
\hline
\end{tabular}


The obtained results suggested that the adsorbed dye cannot be desorbed by simple water, but it is necessary the use of a strong base, as $\mathrm{NaOH}$, indicating also that the attachment of the dye onto the adsorbent occurred through electrostatic interaction.[8]

The excellent performance of the presented material was highlighted by the possibility of re-use of both the adsorbent and dye, for others cycles of adsorption/desorption. Table 1 reports the obtained results after 3 consecutive cycles. From the data in Table 1, it is possible to observe as the DB78 adsorption maintained almost unaltered the performance obtaining the complete removal of the dye from water within 30 minutes. While, the recovery of dye was unfortunately not complete, although efficiencies of $80 \%$ and $90 \%$ were obtained in the first 60 minutes for the $2^{\text {nd }}$ and $3^{\text {rd }}$ cycle, respectively. Further, this paper acquire a great importance considering the real re-use of desorbed DB778 in dying cotton fibers, however this aspect will be discussed at the end of the paper.

3.1.2 Effect of salts. To better understand the mechanism of $\mathrm{DB} 78$ molecule adsorption on $\mathrm{OP}_{\mathrm{P}}$, the process was further studied changing the ionic strength of the solutions. It is worth to mention that textile dyeing processes are generally performed using large amount of salts[9]; as a results this evaluation becomes important for industrial applications. Surprising results were obtained.

Since an amount of $0.25 \mathrm{~g}$ of OPP resulted to be so efficient in removing the dye to use $15 \mathrm{~min}$ for a $100 \%$ removal, these experiments were carried out with the amount of $\mathrm{OP}_{\mathrm{P}}$ lowered at $0.10 \mathrm{~g}$ in order to appreciate the spectral variations. Indeed, if the same experimental conditions were adopted (this aspect is discussed later in the paper), decreasing the weight of adsorbent, the efficiency of dye uptake from water decreased, enabling to follow the absorption spectrum of DB78 at several contact time. Overall, adopting $\mathrm{pH} 2$ as $\mathrm{pH}$ of work, $5 \times 10^{-3} \mathrm{M}$ as dye concentration in $10 \mathrm{~mL}$ and $0.10 \mathrm{~g}$ of pomace, Fig. $6 \mathrm{~A}$ shows the obtained results.

Starting from the results related to $\mathrm{NaCl}$, by adding an appropriate amount of salt, such as $5 \times 10^{-2} \mathrm{M}, 7 \times 10^{-2} \mathrm{M}$ and $1 \times 10^{-1} \mathrm{M}$, in the mixture of dye and pomace, the adsorption process was improved. On the other hand, increasing or decreasing the amount of salt around these values, slight variations were obtained (see also Fig. S1A to better appreciate variations). A similar trend was obtained also change the nature of salt, i.e. $\mathrm{Na}_{2} \mathrm{SO}_{4}$. As an example, Fig. $\mathrm{S} 1 \mathrm{~A}$ and Fig. S1B report the effect on the adsorption process when $\mathrm{Na}_{2} \mathrm{SO}_{4}$ was used at concertation of $1 \times 10^{-1}$ $\mathrm{M}$ and $1 \mathrm{M}$. From these results, along with the role of the electrolyte concentration on the adsorption process, the effect of salts having different nature was also evidenced. The process resulted to be more sensitive by using $\mathrm{Na}_{2} \mathrm{SO}_{4}$.
A high ionic strength was induced under these experimental conditions.

Overall, several reasons can be considered to characterize the behavior observed in presence of salts: (i) the increase of ionic strength induced the compression of the diffuse double layer on the electrostatic attraction and consequently contributed to the adsorption process. Further, the osmotic pressure of solution increased with salt concentration and consequently a concentration polarization layer will be built up by the salt;[30] (ii) the addition of salt rendered the dye molecules more hydrophobic favoring the adsorption process. Indeed, in the presence of counter-ions, the charges associated to DB78 molecules were screened inducing the presence of novel interactions affecting the adsorption process.[4]
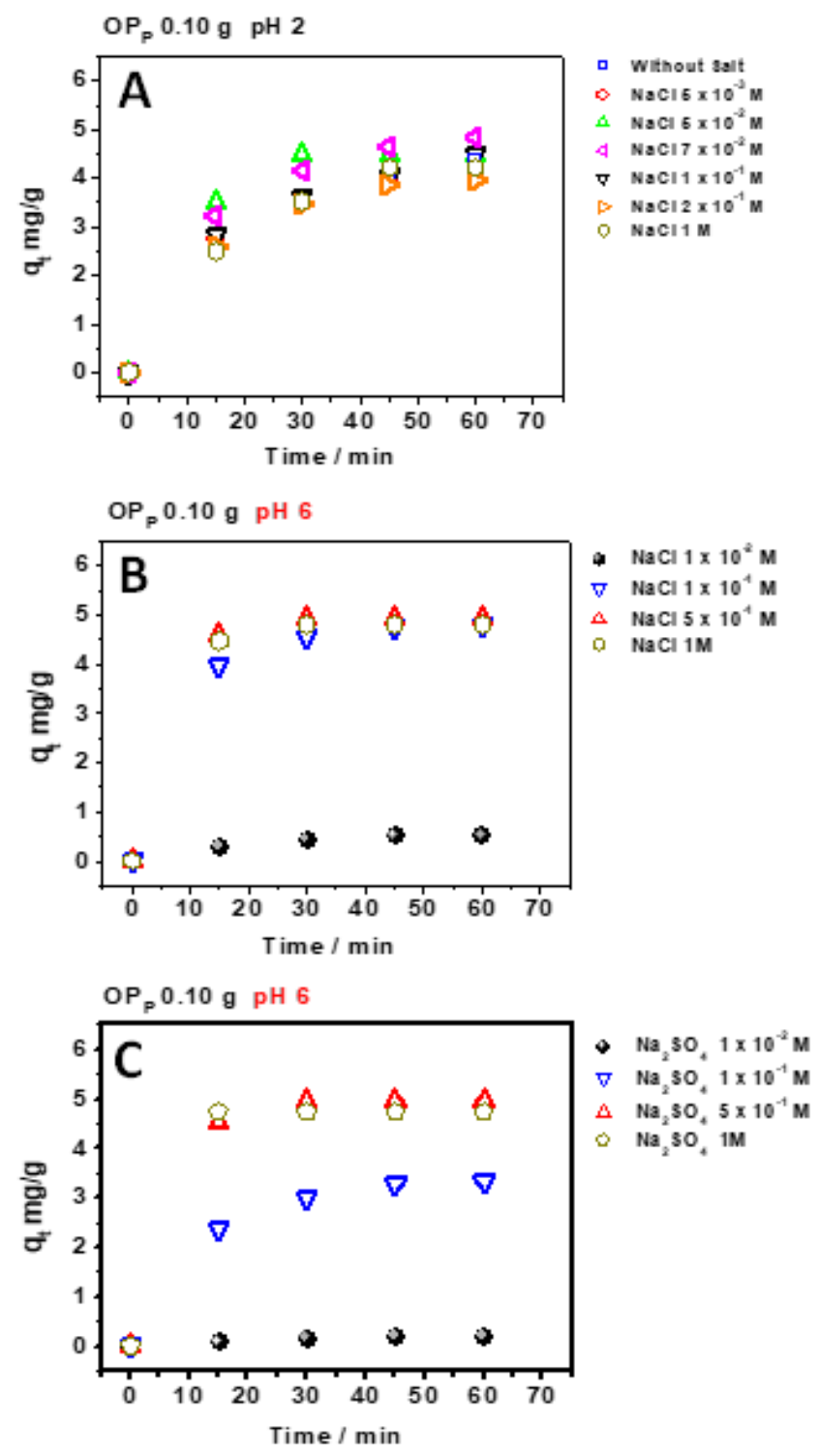

Fig. 6: The effect of salts on the adsorption capacity $q_{t}$ $\left(m g \times g^{-1}\right)$ for DB removal from aqueous solutions $\left(5 \times 10^{-}\right.$ ${ }^{5} \mathrm{M} D \mathrm{DB} 78,0.10 \mathrm{~g} O P_{P}$ in $10 \mathrm{~mL}$ ) at $\mathrm{pH} 2$ evaluating the concentration of $\mathrm{NaCl}$ in the range $5 \times 10^{-3} \mathrm{M}-1 \mathrm{M}(\mathrm{A})$; at $\mathrm{pH} 6$ evaluating the concentration of $\mathrm{NaCl}(\boldsymbol{B})$ and $\mathrm{Na}_{2} \mathrm{SO}_{4}(\mathrm{C})$ in the range $1 \times 10^{-2} \mathrm{M}-1 \mathrm{M}$. 
Accordingly, both the charges of the pomace and DB78 were reduced inducing specific dipole-dipole and hydrogen bonding interactions as well as non-specific induction and dispersion interactions; hydrophobic interactions may also be important.[5] Miyamoto et al.[32] suggested that direct ionic dyes interrupt hydrophobic stacking between cellulose polymer forming hydrogen bonds. Moreover, the planes of glucose rings interacted with the dye aromatic moieties, and the sulfonate groups of the dye molecules interacted with the cellulose hydroxyl groups. In addition, the $\mathrm{CH}$ groups of glucose rings and aromatic moieties of dyes (e.g., naphthalene and biphenyl moieties) interacted weakly.[32] As reported by Porter, the cellulose substrate was considered as heterogeneous material with several accessible regions in which dye molecules can be hosted.[33]

Surprisingly, if on one hand by using $\mathrm{OP}_{\mathrm{P}}$ in neutral medium the adsorption did not take place, on the other hand the use of electrolytes as $\mathrm{NaCl}$ and $\mathrm{Na}_{2} \mathrm{SO}_{4}$ favor the adsorption process also at $\mathrm{pH}$ 6. Fig. $6 \mathrm{~B}$ and Fig. $6 \mathrm{C}$ report the obtained results. In these conditions a high amount of salt was necessary to remove the dye from water with a reverse effect about the nature of used salts. The efficiency of the adsorption process occurred improved by using $\mathrm{NaCl}$. Indeed, by comparing $0.1 \mathrm{M}$ as salt concentration, excellent results were obtained quickly when the adsorption process was studied in presence of $\mathrm{NaCl}$ (Fig. 6B and Fig. 6C) than with $\mathrm{Na}_{2} \mathrm{SO}_{4}$. The differences observed between $\mathrm{NaCl}$ and $\mathrm{Na}_{2} \mathrm{SO}_{4}$ could be ascribed to different effects in screening the charges of DB78 dye and adsorbent. However by comparing Fig. 6A, Fig. 6B and Fig. $6 \mathrm{C}$, the efficiency of the adsorption process appeared overall improved when the electrolytes were added in DB solution at $\mathrm{pH} 6$. So, along with the differences obtained changing the salt and $\mathrm{pH}$, these results suggested that the ionic strength alone cannot be considered to obtain a comprehensive description of the adsorption process. The presence of more important hydrophobic interactions should be considered under these experimental conditions. The thickness of the electric double layer surrounding the dye molecule decreased as the concentration of electrolytes increased allowing the dye molecules to move closer to each other favoring hydrophobic interactions.[34] Not surprisingly, when the release of dye was studied under these conditions, at $\mathrm{pH} 12$, its recovery was not obtained suggesting that the nature of interactions was changed. The results discussed so far suggested as the best work condition was obtained at $\mathrm{pH} 2$ with also the dye recover. Therefore, from now on, the attention was focused on the adsorption process performed at $\mathrm{pH} 2$ evaluating the effect of the adsorbent dosage and dye concentration on the adsorption process.

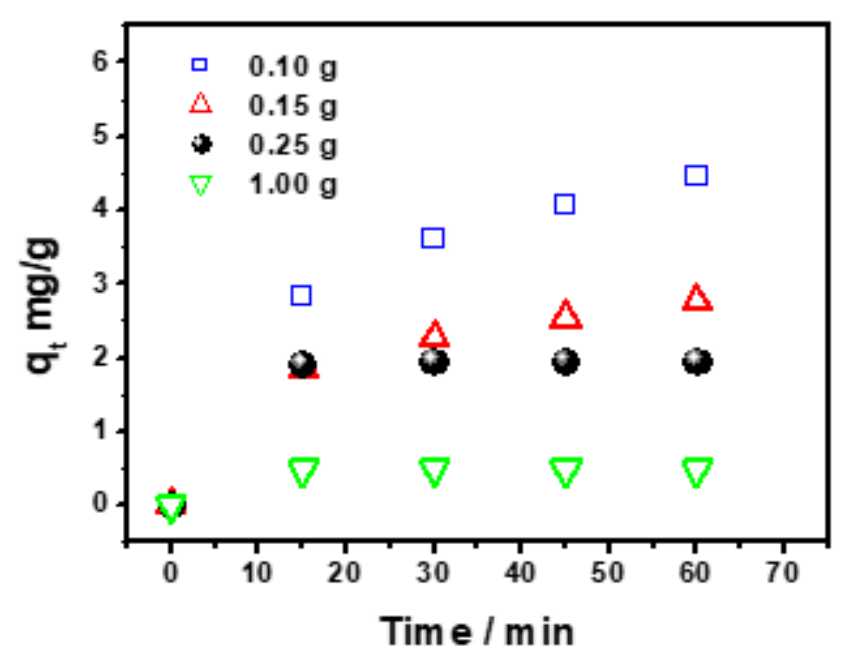

Fig. 7 : Effect of OPP amount (in grams for $10 \mathrm{~mL}$ of dye solution) on the adsorption capacity qt (mg $\times g-1)$ of DB78 dye removal (5×10-5M) from aqueous solution at $\mathrm{pH} 2$.

3.1.3 Adsorbent dosage and dye concentration. The amount of $\mathrm{OP}_{\mathrm{P}}$ was changed from $0.10 \mathrm{~g}$ to $1.00 \mathrm{~g}$ fixing the concentration of DB78 at $5 \times 10^{-5} \mathrm{M}$ in $10 \mathrm{~mL}$. The $\mathrm{q}_{\mathrm{t}}$ values arisen from these experiments were calculated using (1) and are reported in Figure 7. At first glance, observing the time necessary to reach the plateau region, point in which theoretically the dye could be completely adsorbed, increasing the amount of $\mathrm{OP}_{\mathrm{P}}$ increased the removed percentage of dye from water. This behavior was imputed to the presence of more free active sites, able to host dye molecules.[9] On the other hand, when an high amount of $\mathrm{OP}_{\mathrm{P}}$ was used the active sites were not saturated. These results were confirmed when the amount of dye was decreased.[9] Adopting $0.10 \mathrm{~g}$ as fixed amount of $\mathrm{OP}_{\mathrm{P}}$ and $1 \times 10^{-5} \mathrm{M}$ as dye concentration, 15 minutes were enough to completely adsorb DB78 from water (Fig. S2), against 90 minutes necessary to remove it from a concentrated solution, under the same experimental condition. Lowering the concentrations, all dye molecules interacted with the binding sites of the biosorbent. On the other hand, the adsorbent is characterized by a limited number of binding sites, which become saturated at a certain concentration. At higher concentrations, the great part of dye molecules are left in the solution due to the saturation of binding sites, observing a decreased dye removal percentage.

3.1.4 Effect of Temperature. As reported by several papers, studying the adsorption processes, temperature values could be an important factor in affecting the removal of dyes from water.[9] Indeed, in accordance with the thermodynamic nature of process, that can be endothermic or exothermic, changing the temperature can positively or negatively influence the kinetic of adsorption.[35,36] For such purpose, the temperature was changed from $25^{\circ} \mathrm{C}$ to $70^{\circ} \mathrm{C}$ by using the lowest amount of pomace, i.e. $0.10 \mathrm{~g}$, fixing the concentration of dye at $5 \times$ 
$10^{-5} \mathrm{M}$. The obtained results are reported in Figure S3 and are related to the $\mathrm{q}_{\mathrm{t}}$ values obtained under these conditions. The temperature played an important key role during the adsorption process. Passing from $25^{\circ} \mathrm{C}$ to $70^{\circ} \mathrm{C}$ the contact time necessary to remove DB78 from water changed from 90 minutes to 15 minutes, obtained an improvement in the process efficiency similar to that observed using $0.25 \mathrm{~g}$ of pomace at room temperature.

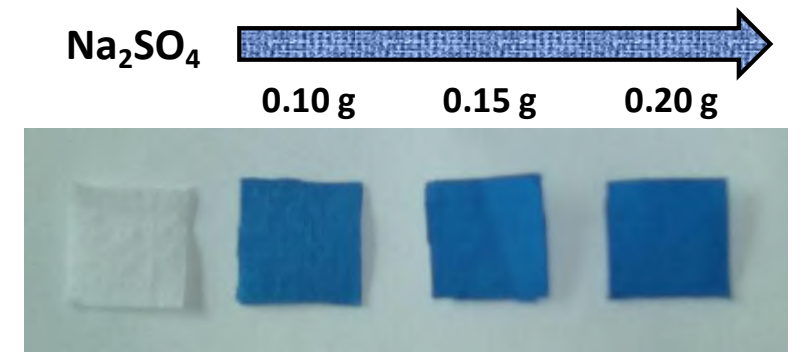

Fig. 8: Camera pictures of dyeing experiments related to desorbed DB78 $(5 \times 10-5 \mathrm{M}$ in $10 \mathrm{~mL})$ on pieces of a cotton textiles with increasing concentrations of sodium sulphate $(10,15$ and $20 \mathrm{~g} / \mathrm{L})$. The experiments were performed at $95^{\circ} \mathrm{C}$ for 60 minutes.

Several factor could considered to justify this behavior: (i) increasing the temperature values, the mobility of dye molecules increased; (ii) or as well described by Akkaya et $a l$.[8], increasing the temperature there is also an increase of the number of active sites available for adsorption on the material surface along with the desolvatation of the adsorbing species and the decrease in the thickness of the boundary layer surrounding the adsorbent, so that the mass transfer resistance of adsorbate in the boundary layer decreased; (iii) last but not least, the swelling effect of the internal structure of the pomace, enabling large dye molecules to penetrate into the structure in higher quantities, that could not be excluded.[9] Indeed, as documented in our recent paper related to disperse dye removal, this effect was very important. This observation is extremely important. Interestingly, during the dyeing process of textiles, hot water is used and the generated wastewater is discharged at considerable high temperatures. These results with the extraordinary effect of salts in dye solution, auxiliary agents used to dyeing the textiles, offer the concrete possibility to use bleached olive pomace for the removal and recover of dye from wastewater. For these purpose, experiments were performed using the desorbed dye from olive pomace to color pieces of textiles.

3.1.5 Dyeing experiments of cotton fibers. The colored solutions obtained after the desorption experiments, were used to dye cotton fibers. White cotton fiber having a superficial area of $2.25 \mathrm{~cm}^{2}$, were placed in contact with 10 $\mathrm{mL}$ of desorbed DB78 solution for 60 minutes at high temperature $\left(95^{\circ} \mathrm{C}\right)$ in presence of increasing amounts of sodium sulfate $(10,15$ and $20 \mathrm{~g} / \mathrm{L})$, as auxiliary agent to color the fibers as suggested by Colorprint Fashion. The effect of salt is clear evident in the camera pictures reported in the Fig. 8. As expected, the adsorption of dyestuff increased increasing the sodium sulfate concentration and it could be ascribed to processes affecting the dyeing method, i.e. the neutralization of negative charge of cotton fibers by sodium ions during the dyeing.

\section{CONCLUSIONS}

In this paper, the operational parameters affecting the adsorption of a commercial direct dye (Direct Blue 78) from wastewater were evaluated, proposing also an alternative use of oil mill waste (named olive pomace, OP) and obtaining excellent results both in the removal and recycle of dye and adsorbent. The biosorbent was modified through previous treatments with $\mathrm{NaOH}$ and $\mathrm{NaClO}_{2}$ for removing impurities and lignin from the surface of the substrate. A cellulosic material was thus obtained. These findings were confirmed using FTIR-ATR spectroscopy, evidencing the main bands of cellulose and cellulose-like structures, arisen after the treatment. A bleached adsorbent was obtained. Experiments were performed both using OP as grains and in powder $\left(\mathrm{OP}_{\mathrm{P}}\right)$. The latter exhibited extraordinary performance removing in 15 minutes the DB78 dye from water using only $0.25 \mathrm{~g}$ of the biosorbent. However, such a behavior was obtained settling the $\mathrm{pH}$ of dye solution at 2 units. The presence of electrostatic interactions inducing the adsorption process was thus evidenced, since at $\mathrm{pH}>2$ there was no dye adsorption. The use of electrolytes as $\mathrm{NaCl}$ and $\mathrm{Na}_{2} \mathrm{SO}_{4}$ further confirm these findings. More specifically the latter salt increased the percentage of dye removal if compared with experiments performed in the presence of $\mathrm{NaCl}$. Overall the influence of ionic strength was taken into account, showing as the process was affected by appropriate amount of salts. These results were better emphasized when the recycle of the dye was studied. Indeed, adopting $\mathrm{pH} 12$ as medium of work, DB78 molecules were desorbed from $\mathrm{OP}_{\mathrm{P}}$ enabling the recycle of both the dye and biosrbent. As an example three cycles of adsorption/desorption were performed showing as the material exhibited the same efficiencies in dye removal with the not complete desorption of dye molecules. A mean value of $80 \%$ was obtained for each cycle. Interestingly, when experiments were performed at pH 6 in presence of the listed salts, the adsorption occurred, suggesting a change in the type of adsorbate/adsorbent interactions, favoring hydrophobic interactions instead of electrostatic ones. In that condition the adsorption occurred with a greater efficiency if compared with results obtained at $\mathrm{pH} 2$, however the desorption of dye was not obtained. Starting from these considerations, the attention was focused on experiments performed at $\mathrm{pH} 2$ studying the effect of the biosorbent amount and dye concentration. Both the experiments

Page | 1568 
involving the change of OPP weight and dye concentration evidenced the role of free active sites hosting DB78 molecules. Indeed, increasing the amount of $\mathrm{OP}_{\mathrm{P}}$ the efficiency in the adsorption process increased. Accordingly, the same results were obtained decreasing the amount of dye. The adsorption process was also influenced by temperature exhibiting an endothermic character. The increase of temperature values induced an increase of the process efficiency.

Thus, the comprehensive investigation about the parameters affecting the adsorption process involving DB78 and $\mathrm{OP}_{\mathrm{P}}$, carefully studied in this paper, evidenced as without salt and in acid conditions, the recycle of dye is possible. Whereas, the presence of salt in neutral medium, although improves the efficiency of the dye removal process, prevents the dye recover. In conclusion, the reuse of dye adsorbed results possible at $\mathrm{pH} 2$ using different amount of $\mathrm{Na}_{2} \mathrm{SO}_{4}$, auxiliary agent generally used during the industrial dying process.

\section{ACKNOWLEDGEMENTS}

We gratefully acknowledge the skillful and excellent technical assistance of Mr. Sergio Nuzzo and the Spanish textile industry, Colorprint Fashion, S.L.

\section{REFERENCES}

[1] A.A. Hermawan, T.K. Bing and B. Salamatinia, "Application and optimization of using recycled pulp for Methylene Blue removal from wastewater: a response surface methodology approach", Int. J. Environ. Sci. Dev., vol. 6(4), pp. 267-274, 2015.

[2] N. Ertugay and F.N. Acar, "Removal of COD and color from Direct Blue 71 azo dye wastewater by Fenton's oxidation: Kinetic study", Arabian J. Chem. Vol. 10(1), pp. 1158-1163, 2017.

[3] F.C. Silva, L.C.B. Lima, R.D.S. Bezerra, J.A. Osajima and E.C. Silva Filho, "Use of Cellulosic Materials as Dye Adsorbents - A Prospective Study", in Cellulose - Fundamental Aspects and Current Trends, M. Poletto and H.L. Ornaghi, Eds. InTech, 2015, pp. 115-132, DOI: $10.5772 / 61343$.

[4] H. Miyamoto, Y. Yuguchi, D.M. Rein, Y. Cohen, K. Ueda and C. Yamane, "Structure of cellulose/direct dye complex regenerated from supercritical water", Cellulose Vol. 23, pp. 2099-2015, 2016.

[5] L.C. Abbott, S.N. Batchelor, L. Jansen, J. Oakes, J.R. Lindsay Smitha and J.N. Moore, "Spectroscopic studies of Direct Blue 1 in solution and on cellulose surfaces: effects of environment on a bis-azo dye", New J. Chem., Vol. 28, pp. 815-821, 2004.

[6] G.L. Bhoosreddy, "Decolorization and biodegradation of Direct Blue 2B by mix consortia of bacillus", IOSR J. Pharm. Biol. Sci., Vol. 9(2), pp. 34-40, 2014.
[7] A. Pirkarami and M.E. Olya, "Removal of dye from industrial wastewater with an emphasis on improving economic efficiency and degradation mechanism", J. Saudi Chem. Soc., Vol. 21, pp. 179-186, 2017.

[8] G.A. Sayğili and F. Güzel, "Chemical modification of a cellulose-based material to improve its adsorption capacity for anionic dyes", J. Dispersion Sci. Technol., Vol. 38(2), pp. 381-392, 2017.

[9] V. Rizzi, F. D'Agostino, P. Fini, P. Semeraro and P. Cosma, "An interesting environmental friendly cleanup: The excellent potential of olive pomace for disperse blue adsorption/desorption from wastewater", Dyes \& Pigm., Vol. 140, pp. 480-490, 2017.

[10] V. Rizzi, A. Longo, P. Fini, P. Semeraro, P. Cosma, E. Franco, R. García, M. Ferrándiz, E. Núñez, J.A. Gabaldón, I. Fortea, E. Pérez and M. Ferrándiz, "Applicative study (Part I): the excellent conditions to remove in batch direct textile dyes (Direct red, Direct blue and Direct yellow) from aqueous solutions by adsorption processes on low-cost chitosan films under different conditions" Adv. Chem. Eng. \& Sci., Vol. 4, pp. 454-469, 2014.

[11]P. Semeraro, V. Rizzi, P. Fini, P. Cosma, E. Franco, R. García, M. Ferrándiz, E. Núñez, J.A. Gabaldón, I. Fortea, E. Pérez and M. Ferrándiz, "Interaction of industrial textile dyes and cyclodextrins" Dyes \& Pigm., Vol. 119, pp. 84-94, 2015.

[12]E. Franco, M. Ferrandiz, S. Moldovan, P. Fini, P. Semeraro, P. Cosma, E. Núñez, J.A: Gabaldón, I. Fortea, E. Pérez and M. Ferrándiz, "Reuse of recovered dyes in cyclodextrins in dyeing process", Vlakna a Textil, Vol. 23(3), pp. 62-68, 2016.

[13] M.A. Martin-Lara, F. Pagnanelli, S. Mainelli, M. Calero and L. Toro, "Chemical treatment of olive pomace: effect on acid-basic properties and metal biosorption capacity", J. Hazard. Mater., Vol. 156, pp. 448-457, 2008.

[14]F. Luzia, E. Fortunati, D. Puglia, M. Lavorgna, C. Santulli, J.M. Kenny and L. Torre, "Optimized extraction of cellulose nanocrystals from pristine and carded hemp fibres", Ind. Crops Prod. Vol. 56, pp. 175-186, 2014.

[15] J.I. Moran, V.A. Alvarez, V.P. Cyras and A. Vazquez, "Extraction of cellulose and preparation of nanocellulose from sisal fibers", Cellulose, Vol. 15, pp. 149-159, 2008.

[16]D. Markovic, B. Jokic, Z. Saponjic, B. Potkonjak, P. Jovancic and M. Radetic, "Photocatalytic degradation of Dye C.I. Direct Blue 78 using TiO2 nanoparticles immobilized on recycled wool-based nonwoven material", Clean: Soil, Air, Water, Vol. 41(10), pp. 1002-1009, 2013. 
[17] H. Biglari, N. Javan, R. Khosravi and A. Zarei, "Direct Blue 71 removal from aqueous solutions by adsorption on pistachio hull waste: equilibrium, kinetic and thermodynamic studies", Iran. J. Health Sci., Vol. 4(2), pp. 55-70, 2016.

[18] J.R. Baseri, P.N. Palanisamy and P. Sivakumar, "Comparative studies of the adsorption of Direct Dye on activated carbon and conducting polymer composite", E-J. of Chem., Vol. 9(3), pp. 1122-1134, 2012.

[19] M.A. Martín-Lara, F. Hernainz, M. Calero, G. Blazquez and G. Tenorio, "Surface chemistry evaluation of some solid wastes from olive-oil industry used for lead removal from aqueous solutions", Biochem. Eng. J., Vol. 44, pp. 151-159, 2009.

[20] T. Akar, I. Tosuna, Z. Kaynak, E. Ozkara, O. Yeni. E.N. Sahin and S.T. Akar, "An attractive agroindustrial by-product in environmental cleanup: dye biosorption potential of untreated olive pomace", J. Hazard. Mater. Vol. 166(2-3), pp. 1217-1225, 2009.

[21] A. Hawari, M. Khraisheh, A. Mohammad and M.A. Al-Ghouti, "Characteristics of olive mill solid residue and its application in remediation of $\mathrm{Pb} 2 \mathrm{p}, \mathrm{Cu} 2 \mathrm{p}$ and Ni2p from aqueous solution: mechanistic study", Chem. Eng. J, Vol. 251, pp. 329-336, 2014.

[22] A. Mousa, G. Heinrich, U. Gohs, R. Hassler and U. Wagenknecht, "Application of renewable agro-wastebased olive pomace on the mechanical and thermal performance of toughened PVC", Polym.-Plast. Technol. Eng., Vol. 48, pp. 1030-1040, 2009.

[23] H.A. Omar and L. Abd El -Baset Attia, "Kinetic and equilibrium studies of cesium-137 adsorption on olive waste from aqueous solutions", Radiochemistry, Vol. 55, pp. 497-504, 2013.

[24] T. Kondo, "The assignment of IR absorption bands due to free hydroxyl groups in cellulose", Cellulose, Vol. 4, pp. 281-292, 1997.

[25] M. Poletto, H.L. Ornaghi, J. Zattera and A.J. Zattera, "Native Cellulose: Structure, Characterization and Thermal Properties", Materials, Vol. 7, pp. 61056119, 2014.
[26] A. Hawe, M. Sutter and W. Jiskoot, "Extrinsic Fluorescent Dyes as Tools for Protein Characterization", Pharm. Res., Vol. 25, pp. 14871499, 2008.

[27] A. Badiei, A. Mirahsani, A. Shahbazi, H. Younesi and M. Alizadeh, "Adsorptive removal of toxic dye from aqueous solution and real industrial effluent by tris (2aminoethyl) amine functionalized nanoporous silica", Environ. Prog. Sustainable Energy, Vol. 33, pp. 12421250, 2014.

[28] Y. Safa and H.N. Bhatti, "Adsorptive removal of direct dyes by low cost rice husk: Effect of treatments and modifications", Afr. J. Biotechnol., Vol. 10(16), pp. 3128-3142, 2011.

[29] M.F. Abid, M.A. Zablouk and A.M. Abid-Alameer, "Experimental study of dye removal from industrial wastewater by membrane technologies of reverse osmosis and nanofiltration", Iran. J. Environ. Health Sci. Eng., Vol. 9, pp. 17, 2012.

[30]D.B. Jirekar, A.A. Pathan and M. Farooqui, "Adsorption studies of methylene Blue Dye from aqueous solution onto phaseolus aureus biomaterials", Orient. J. Chem., Vol. 30(3), pp. 1263-1269, 2014.

[31] J.J. Porter, "Dyeing equilibria: interaction of direct dyes with cellulose substrates", Color. Technol., Vol. 118, pp. 238-243, 2002.

[32] M.R.R. Kooh, M.K. Dahri, L.B.L. Lim and L.H. Lim, "Remediation of direct blue 71 wastewater by salting out processes using inorganic salt solutions and seawater", Journal of Environment \& Biotechnology Research, Vol. 6, pp. 53-57, 2017.

[33] S.R. Shirsath, A.P. Patil, R. Patil, J.B. Naik, P.R. Gogate and S.H. Sonawane, "Removal of Brilliant Green from wastewater using conventional and ultrasonically prepared poly (acrylic acid) hydrogel loaded with kaolin clay: a comparative study", Ultrason. Sonochem., Vol. 20(3), pp.914-923, 2013.

[34] G. Annadurai, L.Y. Ling and J.F. Lee, "Adsorption of reactive dye from an aqueous solution by chitosan: isotherm, kinetic and thermodynamic analysis", J. Hazard. Mater., Vol.152, pp. 337-346, 2008. 
Supporting Material

Operational parameters affecting the removal and recycling of direct blue industrial dye from wastewater proposing bleached oil mill waste as alternative adsorbent material
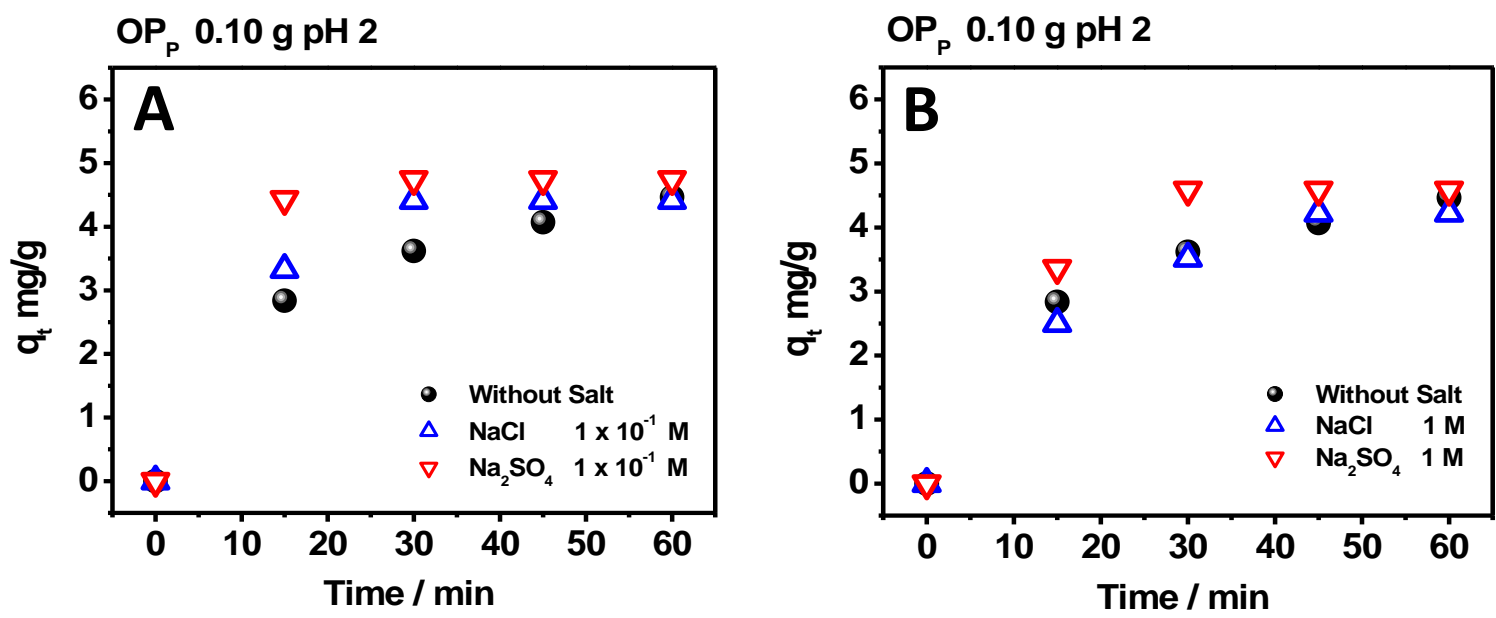

Fig.S1: The effect of salts on the adsorption capacity $q_{t}\left(\mathrm{mg} \mathrm{g}^{-1}\right)$ for $\mathrm{DB}$ removal from aqueous solutions $\left(5 \times 10^{-5} \mathrm{M} \mathrm{DB}, 0.10\right.$ $g \mathrm{OP}_{\mathrm{P}}$ in $10 \mathrm{~mL}$ ) at $\mathrm{pH} 2$ comparing the efficiency between $\mathrm{NaCl}$ and $\mathrm{Na}_{2} \mathrm{SO}_{4}$ at $1 \times 10^{-2} \mathrm{M}$ and $1 \mathrm{M}$.

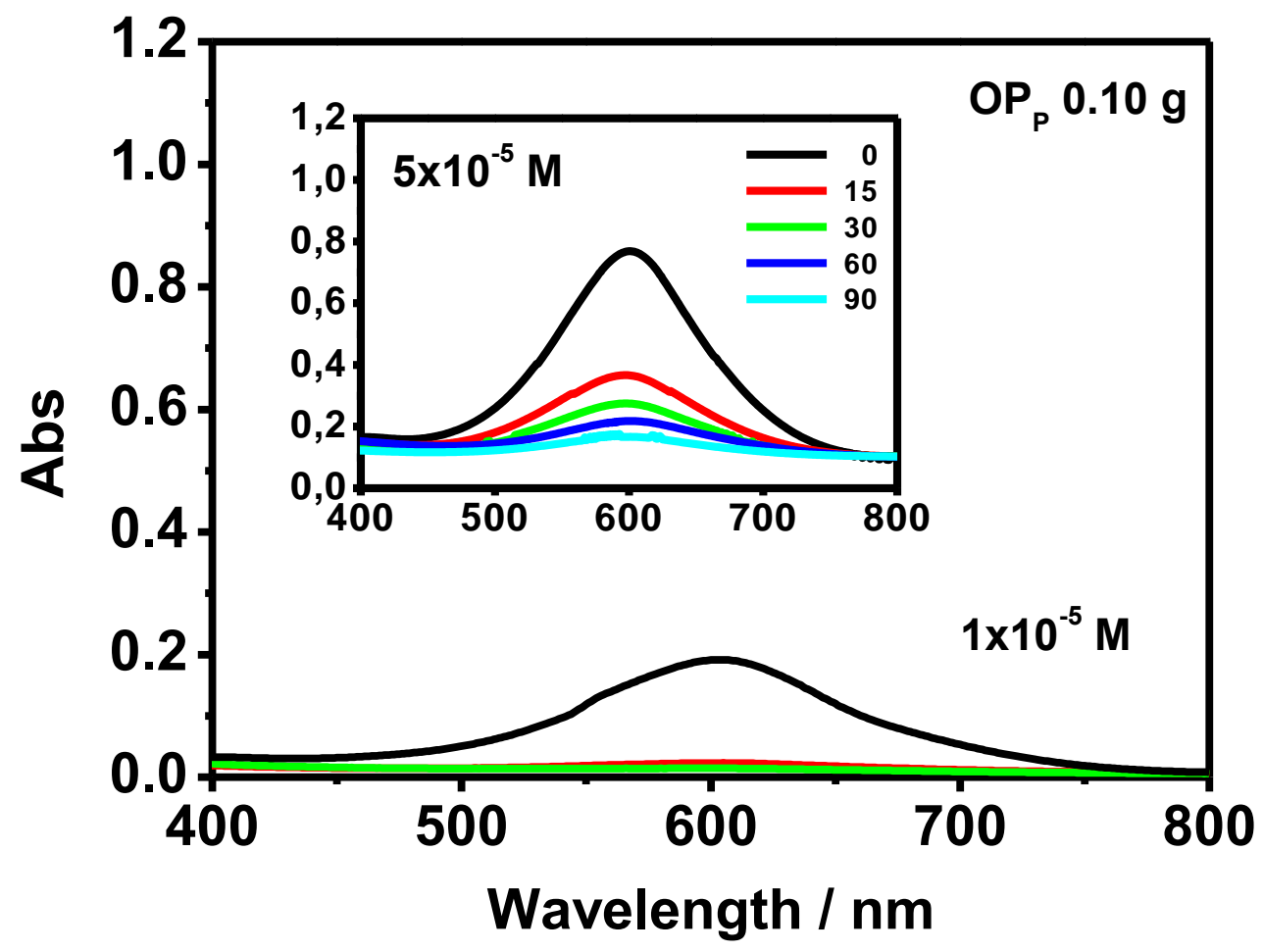

Fig.S2: Effect of $D B$ dye concertation $\left(5 \times 10^{-5} \mathrm{M}\right.$ and $1 \times 10^{-5} \mathrm{M}$, in $\left.10 \mathrm{~mL}\right)$ on the adsorption capacity $q_{t}\left(\mathrm{mg}^{-1}\right)$ using $0.10 \mathrm{~g}$ of $O P_{P}$ at $p H 2$. 


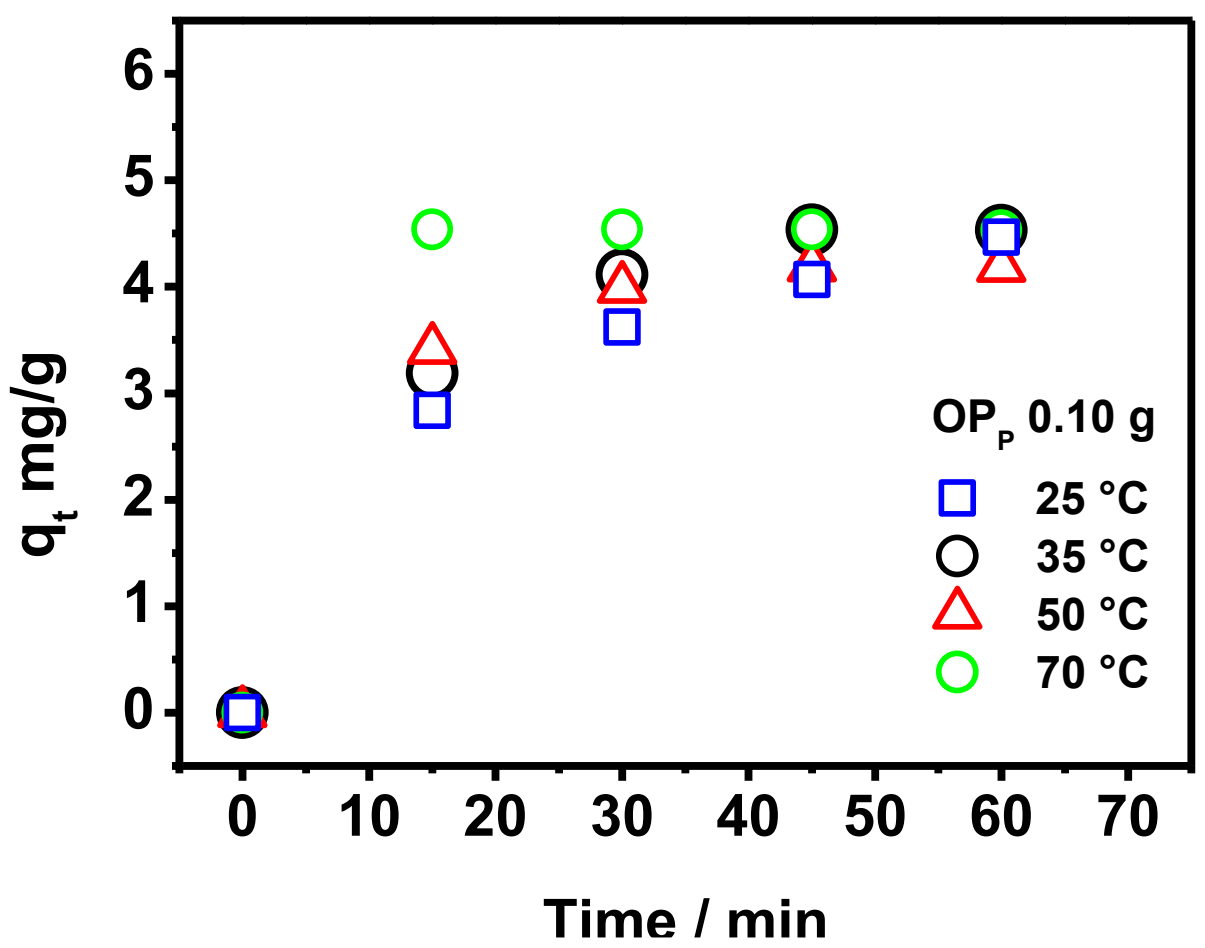

Fig.S3: Effect of temperature values ranging from $2^{\circ} \mathrm{C}$ to $70^{\circ} \mathrm{C}$ on the adsorption capacity $q_{t}\left(\mathrm{mg}^{-1}\right)$ of DB dye removal $\left(5 \times 10^{-5} \mathrm{M}\right)$ from aqueous solution at $\mathrm{pH} 2 ; 0.10 \mathrm{~g}$ of $\mathrm{OP}_{P}$ were used. 